\title{
ОБРАЗОВАТЕЛЬНОЕ ПРОСТРАНСТВО СОЮЗНОГО ГОСУДАРСТВА БЕЛАРУСИ И РОССИИ КАК РЕСУРС СОПРЯЖЕНИЯ И РАЗВИТИЯ ЕВРАЗИЙСКОЙ ИНТЕГРАЦИИ
}

\begin{abstract}
Аннотация. Положение образовательных и экономических конструктов западноевропейской интеграции характеризуется наиболее современным и продвинутым шестым технологическим укладом. Эволючии и генезису этой модели во многом способствовала развитая и мобильная образовательная интеграция. Прогрессивные и качественные изменения в работе экономических систем евразийской интеграции не будут в будущем возможны без устойчивой работы системы высшего образования. В статье приведены институционально-академические положения в образовательной системе Союзного государства. В работе выявлень наиболее значимые и ощутимые для союзной образовательной интеграции недостатки $u$ приведены возможные пути их решения.
\end{abstract}

Ключевые слова: высшее образование, интеграция, унификаџия, цуифровизация, сетевизаичия, Союзное государство, Евразийский экономический союз, Евразийская ассоџиация университетов, академическая мобильность.

Современные политические факторы развития Беларуси определяются активным участием государства в деятельности интеграционных объединений экономического и общественно-политического профилей. На протяжении более чем двадцати лет внешняя и внутренняя политика Беларуси неразрывно связана с активностью страны в составе СНГ, Союзного государства Беларуси и России, Евразийского экономического союза (ЕАЭС), Таможенного союза, ОДКБ ${ }^{1}$. Среди политико-правовых, экономических и социальных вопросов, решаемых под эгидой этих интеграционных объединений, недостаточно основательно раскрыта проблема сопряжения высшего образовательного пространства.

Строительство единого научно-образовательного пространства Союзного государства является приоритетом в вопросах белорусско-российской интеграции. Однако по-прежнему отсутствует действенное основание для использования потенциала этого приоритета. Актуальность проблемы сопряжения высшего образования Союзного государства основана на следующих тезисах:

- с региональной точки зрения процессы гармонизации и унификации системы высшего образования Союзного государства Беларуси и России основываются на более 550 догово́рах о взаимодействии ${ }^{2}$. Однако далеко не все документы приносят для образовательной инте-

(C) Макареев Николай Александрович - выпускник УО «Гродненский государственный университет имени Янки Купалы», историк, магистр политических наук. Адрес: 230023, Беларусь, Гродно, ул. Ожешко, д. 22.E-mail: makareev.n@mail.ru.

DOI: http://dx.doi.org/10.15211/vestnikieran32019133139

${ }^{1}$ Министерство иностранных дел Республики Беларусь. Беларусь и международные организации. 2017. URL: http://mfa.gov.by/mulateral/organization (дата обращения: 13.05.2018).

${ }^{2}$ Новости Сибирской науки. О сотрудничестве России и Беларуси в сфере высшего образования. 2017. URL: http://www.sib-science.info/ru (дата обращения: 11.05.2017). 
грации заявленный в них эффект,

- существует необходимость создания таких условий интеграционной экономики, науки, образования, аттестации и переподготовки научных кадров, которые стали бы соответствием шестому технологическому укладу мировой экономики ${ }^{1}$,

- недостаточно проводится работа над созданием общей стандартизации научных и учебных планов в высшей школе, оптимизации программ исходя из потребностей и целей Союзного государства, наращивания академической мобильности государств - членов Союзного государства и ЕАЭС.

В современных условиях высшее образовательного пространство Союзного государства и ЕАЭС основано на конкурентном историческом преимуществе, уникальности и возможностях высших образовательных систем, которые на ещё более высоком уровне необходимо приобщать к развитию общего образовательного пространства ЕАЭС ${ }^{2}$. В мае 2018 г. во время заседания Евразийского экономического совета, президент Российской Федерации В.В. Путин обратил внимание участников на то, что странам Евразийского экономического союза необходимо интенсифицировать развитие интеграционных процессов в социально-гуманитарной сфере, образовании ${ }^{3}$. Таким образом, строительство единого научно-образовательного пространства, согласованной политики в сфере высшей школы Союзного государства и ЕАЭС является императивом интеграционного процесса ${ }^{4}$. На этот тезис акцентировала внимание Председатель Совета Федерации РФ Валентина Матвиенко во время открытия заседания правления интеграционного клуба при Председателе Совета Федерации. Движущими силами формирования образовательных взаимозависимостей между высшими школами Союзного государства и ЕАЭС, которые призваны обеспечивать регулирование деятельности и сближение систем высшего образования Беларуси и России с третьими странами в рамках ЕАЭС, являются национальные и наднациональные институциональные ведомства. К таковым относятся совместные коллегии министерств образования двух государств, которые предлагают к общественно-политическому обсуждению интеграционные проекты в области высшего образования, требующие принятия решений на уровне правительств и глав государств. Унификация образовательных стандартов и программ Союзного государства, создание совместных законодательных инициатив в структуре высшего образования разрабатываются и выносятся на обсуждение членами Парламентского собрания Союзного государства ${ }^{5}$.

Парламентское собрание осуществляет свои полномочия при помощи назначаемых из числа парламентариев Беларуси и России членов комиссий и рабочих групп по вопросам расширения и углубления интеграции высшего образования. Совет министров Союзного государства способствует проведению согласованной политики в области высшей школы. Ответственным институциональным органом за подготовку заседаний профильных министерств и ведомств Союзного государства, формирование проектов и планов работы отраслевых образовательных учреждений является постоянный комитет Союзного государства. Согласованную политику стран в научной сфере совместно с органами исполнительной власти претво-

\footnotetext{
${ }^{1}$ Фонд президентских грантов. Поддержка и развитие интеграционных процессов в образовательном пространстве Евразийского союза. 2018. URL: https://xn--80afcdbalict6afooklqi5o.xn--p1ai/public/application/item?id=9b501 a11-c086-47df-b3f9-8aa446861ea5 (дата обращения: 14.05.2018).

Там же.

3 Белорусское телеграфное агентство. Путин призвал страны ЕАЭС усилить развитие интеграционных процессов. 2018. URL: http://www.belta.by/politics/view/putin-prizval-strany-eaes-usilit-razvitie-integratsionnyh-protsessov302588 2018/?utm source=belta\&utm medium=social\&utm campaign=vk belta (дата обращения: 14.05.2018).

${ }^{4}$ Международная жизнь. Создание единого образовательного пространства - ключевая задача Евразийской интеграции. 2016. URL: https://interaffairs.ru/news/show/16424 (дата обращения: 14.05.2018).

5 Официальный сайт постоянного комитета Союзного государства. Деятельность постоянного комитета. 2018.

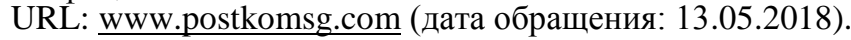


ряет в жизнь Межакадемический совет по проблемам развития Союзного государства.

Академические институты, осуществляющие интеграционную функцию в сфере высшего образовательного пространства Союзного государства, представлены Российско-Белорусским университетом, Минским филиалом Российского экономического университета им. Г.В. Плеханова, филиалом Российского государственного социального университета. Основу учебных программ представленных учреждений составляют российские образовательные стандарты. В 2011 г. постановлением Высшего Государственного Совета Союзного государства была утверждена Концепция социального развития, которая включает инструменты и процедуры формирования единого образовательного пространства, в том числе, согласование образовательных стандартов ${ }^{1}$.

Данные нормативные акты впервые представили собой правовую основу для ведения полноценного и конструктивного диалога в целях сопряжения высшего образования Союзного государства. Создание единых институциональных ориентиров Союзного государства в рамках высшего образования является одним из стержневых параметров в его развитии. Глобальным институциональным органом в рамках ЕАЭС, в сферу которого входят функции координации деятельности системы высшего образования государств участников, является Евразийская ассоциация университетов (далее ЕАУ). Истоки ЕАУ как основополагающего объединения высших учебных заведений государств - участников ЕАЭС относятся к 1989 г. ЕАУ является одной из крупнейших международных организаций университетов. В ассоциацию входят национальные университеты стран СНГ, региональные университеты и высшие учебные заведения стран ЕАЭС. ЕАУ объединяет 139 университетов стран СНГ. Высшим руководящим органом является Съезд Ассоциации. Всего состоялось 16 съездов, которые проходили в Москве, Киеве, Баку, Ашхабаде, Казани, Минске, Астане. На Съездах ЕАУ рассматриваются вопросы состояния и перспектив образовательных траекторий стран ЕАЭС, обсуждаются задачи сохранения единого образовательного пространства и обеспечения эквивалентности университетских дипломов, развитие сотрудничества университетов, совершенствование образования. Руководство ЕАУ осуществляется Советом и Исполнительным комитетом ${ }^{2}$.

Работа с молодёжью и трудовыми коллективами университетов является наиболее важным аспектом работы организации. В рамках ЕАУ учреждены Студенческая ассоциация университетов и Евразийская ассоциация профсоюзных организаций, которые регулярно проводят свои съезды, направленные на укрепление связей. При Ассоциации действуют центры по отдельным направлениям сотрудничества университетов. Евразийская ассоциация университетов аккредитована при Межпарламентской Ассамблее стран СНГ и Совете по сотрудничеству в области образования государств СНГ. Свою деятельность ассоциация осуществляет посредством многочисленных конференций, форумов, межвузовских связей и контактов, проводит международные научно-практические конференции, инициирует углубление гуманитарного сотрудничества стран Союзного государства, СНГ И ЕАЭС. В апреле 2016 г. ректор Томского государственного университета Э.В. Галажинский во время выступления на Совете ЕАУ обозначил, что развитие экономической интеграции в рамках ЕАЭС требует не только масштабного сотрудничества в сфере науки и технологий, коммерциализации и трансфера наукоёмких и высокотехнологических разработок, но и, прежде всего, совместной подготовки высококвалифицированных кадров ${ }^{3}$.

\footnotetext{
${ }^{1}$ Новости Сибирской науки. О сотрудничестве России и Беларуси в сфере высшего образования. 2017. URL: http://www.sib-science.info/ru (дата обращения: 11.05.2017).

${ }^{2}$ Евразийская ассоциация университетов. Об ассоциации. 2017. URL: http://www.eau-msu.ru/ (дата обращения: 12.05.2018)

${ }^{3}$ Там же.
} 
Процессы цифровизации и сетевизации системы высшего образования не оставили в стороне систему высшего образования Союзного государства и ЕАЭС. 12 апреля 2016 г. на заседании Совета ЕАУ был подписан меморандум о взаимопонимании, который предусматривает создание Евразийского сетевого университета (далее ЕСУ). Согласно содержанию меморандума, ЕСУ призван выступить одним из участников институциональных основ развития пространства высшего образования государств ЕАЭС, быть проводником принятия решений на евразийском пространстве в области высшего образования. ЕСУ призван аккумулировать деятельность профильных министерств и ведомств, а также научно-образовательных организаций стран ЕЭАС, организовывать совместную сетевую работу ведущих университетов, научных центров и других учреждений с целью продвижения развития евразийской интеграции. Однако на сегодняшний день существуют ряд проблем союзников по ЕАЭС связанных с сетевым взаимодействием стран в области высшего образования. Так, например, главной составляющей электронных коммуникаций в сфере высшего образования Союзного государства и ЕАЭС является ориентация на стандарты стран Евросоюза, несовершенство и неразвитость нормативно-правовой базы, отсутствие научного обоснования и недостаточное финансирование.

Для решения возникших в связи цифровизацией высшей школы проблем, исследователи информационно-коммуникационных проектов на постсоветском пространстве А.О. Лебедев и С.Э. Савзиханова предложили произвести объединение интеграционных ресурсов учреждений высшего образования Союзного государства и ЕАЭС с целью развития виртуальных консорциумов и объединений университетов, которые смогли бы работать в шестом технологическом укладе. Таким образом, отметим, что страны Евразийского образовательного пространства нуждаются в трансформации, основанной на новом характере социальных связей, при активном использовании информационно-коммуникационных технологий, электронных образовательных ресурсов. Первостепенная роль в этом деле принадлежит университетам, которые должны активизировать сотрудничество друг с другом с помощью реализации совместных образовательных и научно-исследовательских программ; интенсификации академического и межбиблиотечного обмена, дистанционного обучения; сотрудничества в сфере межрегионального межвузовского взаимодействия, в том числе через создание межрегиональных вузовских консорциумов, международных научных коллабораций, центров коллективного пользования. Важной составной частью этого процесса являются субъекты высшего образовательного пространства Союзного государства и ЕАЭС. В качестве субъектов сопряжения выступают представители студенческого состава, бакалавриата, магистратуры, аспирантуры, докторантуры учреждений высшего образования.

Министерство образования и науки Российской Федерации в 2018 г. озвучило следующие показатели интеграции сфер высшего образования Союзного государства: количество студентов из Беларуси обучающихся в российских вузах выросло с 4 тыс. в начале первого десятилетия XXI в. до 24-25 тыс. на рубеже 2017/2018 гг. ${ }^{1}$ Однако более $2 / 3$ из них обучаются в российских вузах заочно или дистанционно. Белорусских студентов-очников в российских вузах обучается примерно в четыре раза меньше, чем студентов из Казахстана. Количество очных студентов из Беларуси в РФ сопоставимо с числом студентов из Киргизии и Армении от 2,5 то 3,5 тысяч. Российских студентов в Беларуси обучается около тысячи человек. Исходя из приведённых сведений, с полной уверенностью нельзя говорить о соответствии интеграции Союзного государства в области высшего образования задачам становления общего об-

\footnotetext{
${ }^{1}$ Новости Сибирской науки. О формировании общего научно-образовательного пространства Союзного государства. 2018. URL: http://www.sib-science.info/ru/heis/sergeev-nauka-23012018 (дата обращения: 14.05.2018).
}

Научно-аналитический вестник ИЕ РАН, 2019, №3 
разовательного пространства Союзного государства, поскольку именно студенты-очники, получая образование в России либо в Беларуси, становятся носителями не только научных знаний, но и в значительной степени общих ценностей двух стран. Интеграционные же процессы в Евросоюзе при всех политических кризисах развивались и развиваются куда более успешно, нежели чем в Евразии при участии как Союзного государства, так и ЕАЭС. Поэтому на сегодняшний период важно продолжить формировать общесоюзные «профессиональные сети», которые позволили бы скрепить не только белорусско-российское технологическое, но и цивилизационное пространство. Работа в этом направлении требует серьёзного уточнения, в некоторой степени реанимации и укрепления.

В качестве первых шагов, которые следовало бы совершить для улучшения ситуации в работе по интеграции высшего образовательного пространства - это системное и взаимное увеличение квот государственных стипендий для обучения в образовательных учреждениях как России, так и Беларуси. В 2015/2016 и в 2016/2017 учебных годах было выделено всего 28 стипендий. Отсутствует механизм взаимного льготирования для одарённых учащихся, победителей олимпиад, в том числе международных на поступление как в российские, так и в белорусские университеты. Этот факт говорит о том, что в совершенствовании нуждается соответствующее законодательство, предоставляющее возможность гражданам Союзного государства и в перспективе - гражданам стран ЕАЭС поступать без экзаменов в российские либо белорусские вузы ${ }^{1}$.

По-прежнему остаётся актуальным вопрос о взаимоотношении белорусской системы высшего образования и Болонской системы, который, без сомнения, влияет на интеграцию высшего образования Союзного государства. Сформировался по сути единый в регионе западноевропейских центр образовательной интеграции, который, как оказалось, призван быть инструментом не только повышения качества мировой образовательной системы, но и кластером продвижения в общественное сознание западной геополитической ориентации, соответствующих идеологических «ценностей», а также «выкачивания мозгов» из стран - субъектов Союзного государства. Остаётся не решённым вопрос о создании концепции развития общего образовательного и научно-технологического пространства России и Беларуси, поскольку мы имеем только равные права граждан Союзного государства в получении образования на всей его территории ${ }^{2}$.

Таким образом, Союзное государство и евразийская интеграция нуждаются в развитии тесных связей в области гуманитаристики, которая пребывает в безнадёжном проигрыше экономическому вектору сотрудничества. В этой связи усилия важно направлять на формирование общесоюзной системы образования со схожими программами развития высших образовательных систем. В нынешних условиях совершать эти шаги будет трудно, поскольку многие категории систем высшего образования находятся на разных стадиях и уровнях развития. Однако компенсировать утраченное время можно при помощи конкретной проектной базы межвузовского взаимодействия. К таковой можно отнести взаимообмен и предоставление университетами своих материальных возможностей в виде лабораторий, технопарков, производственных цехов для реализации совместных программ и проектов, внедрение разработок в реальный сектор экономики, определение потенциальных направлений для эффективного взаимодействия по проведению фундаментальных и прикладных исследований вузов и научно-исследовательских институтов, вовлечение молодых исследователей в тематическую работу проводимую кафедрами, факультетами и исследовательскими центрами вузов, что, в свою

\footnotetext{
${ }^{1}$ Там же.

${ }^{2}$ Там же.
} 
очередь, обеспечит нужную базу для получения практических знаний и соответственно интегральную конкурентоспособность выпускников вузов. Институциональные, нормативно-правовые качества функционирования высшего образовательного пространства Союзного государства имеют дуальную основу развития. С одной стороны, они во многом зависимы от экономических и политических аспектов стран-участниц интеграции, с другой - выступают в качестве драйверов укрепления ЕАЭС. Союзники должны быть друг для друга свободными коридорами и лабораториями для интеграции структур высшего образования с единым пространством культуры, символов и смыслов.

\section{Список литературы}

Абламейко С.В. Единое образовательное пространство Евразийских университетов: перспективы развития. Информационно-технологическое обеспечение образовательного процесса государств участников СНГ. Минск, Беларусь, январь 2012. С.13-31.

Акулик А.К., Бобков В.А. Беларусь в интеграционных проектах, Беларус. навука, Минск, 2011. С. 43-82, 248-290, 291-310.

Базанов А.В., Криштапович Л.Е. Союзное государство как императив развития Беларуси и России в современном мире. Информ-аналит. центр при Адм. Президента Респ. Беларусь, Минск: Белорус. дом печати, 2011. 432 с.

Бадмаев В.Н. Евразийское образовательное пространство и Евразийский потенциал университетов. Вестник МГТУ, №3, 2016. С. 2-6.

Дробышева Л.В. Сотрудничество России со странами СНГ в сфере культурно-образовательной политики в 1991-2015 гг. Известия ВГПУ, 2017. С. 183-188.

Енин Ю.В. Формирование единого образовательного и научно-производственного пространства в условиях Евразийской экономической интеграции. Евразийская экономическая интеграция, №2(15), 2012. С. 43-50.

Караткевич А.Г., Головин Ю.А. Процесс интеграции Российской Федерации и Республики Беларусь в рамках Союзного государства. Вестник КГУ имени Н.А. Некрасова, №6, 2014. С. 290-296.

Лебедев А.О. Сетевое взаимодействие стран СНГ в сфере высшего образования как форма региональной интеграции. Научные ведомости, №15(158), 2013. С. 25-31.

Овезова У.А., Вагнер У.А. Сотрудничество стран СНГ и России в области образования. Теория и практика общественного развития, №11, 2012. С. 181-183.

Панков Д.А. Концепция международного сетевого взаимодействия учреждений высшего образования Союзного государства, осуществляющих подготовку экономических кадров. Бухгалтерский учёт и анализ, №11, 2017. С. 32-51.

\section{References}

Ablameiko S.V. Unified Educational Space of Eurasian Universities: Development Prospects, Information and Technology Support for the Educational Process of the CIS Member States, Minsk, Belarus, January 2012. P.13-31.

Akulik A.K., Bobkov V.A. Belarus in integration projects, Belarus. the director, Minsk. 2011. P. 43-82; 248-290; 291-310.

Bazanov A.V., Krishtapovich L.E. The Union State as an Imperative for the Development of Belarus and Russia in the Modern World, Inform.-Analit. center at the Adm. President of the Republic of Cyprus. Belarus, Minsk: Belarusian. house of the seal, 2011. 432 sec. 
Badmaev V.N. The Eurasian educational space and the Eurasian potential of universities. Bulletin of the Moscow State Technical University, №3, 2015. P. 2-6.

Drobysheva L.V. Russia's cooperation with the CIS countries in the sphere of cultural and educational policy in 1991-2015. Proceedings of the VSPU, 2017. P. 183-188.

Enin $\mathrm{Yu}$.V. Formation of a single educational and scientific-production space in the conditions of the Eurasian economic integration. Eurasian Economic Integration, №2(15), 2012. P. 43-50.

Karatkevich A.G., Golovin Yu.A. The process of integration of the Russian Federation and the Republic of Belarus within the framework of the Union State. Vestnik KSU na NA. Nekrasov, №6, 2014. P. 290-296.

Lebedev A.O. Networking of CIS Countries in Higher Education as a Form of Regional Integration. Scientific Bulletin, №15(158), 2013. P. 25-31.

News of Siberian Science. On the formation of a common scientific and educational space of the Union State. 2018. URL: http://www.sib-science.info/en/heis/sergeev-nauka-23012018 (accessed date: 14.05.2018).

Ovezova U.A., Wagner U.A. Cooperation of the CIS countries and Russia in the field of education. Theory and practice of social development, №11,2012. P. 181-183.

Pankov D.A. The Concept of the International Networking of Higher Education Institutions of the Union State, Training the Economic Staff. Accounting and Analysis, №11, 2017. P. 32-51.

\section{Educational Space of the Union State of Belarus and Russia as a Resource of the Integration and Development of the Eurasian Integration}

Author. Nikolai Makareev, Graduate from Yanka Kupala State University of Grodno, historian. Master of Political Sciences. Address: 22, Ozheshko str., Grodno, Belarus, 230023. E-mail: makareev.n@mail.ru.

Abstract. The situation of educational and economic constructs of Western European integration is characterized by the most modern and advanced sixth technological order. The evolution and genesis of this model was largely contributed by the developed and mobile educational integration. It is obvious that any progressive and qualitative changes in the work of the economic systems of the Eurasian integration will not be possible in the future without the stable operation of the structural components of the Higher Academic Environment. The paper is an attempt to rethink the situation of institutional, political and academic affairs in the educational system of the Union State as one of the most important models of the Eurasian integration. In the work the basic imperfections for the subjects and objects of the Union Educational Integration are revealed and possible ways of their solution are presented.

Keywords: higher education, integration, unification, digitalization, networkization, Union State, Eurasian Economic Union, Eurasian Association of Universities, academic mobility.

DOI: http://dx.doi.org/10.15211/vestnikieran32019133139 